University of Montana

ScholarWorks at University of Montana

Graduate Student Theses, Dissertations, \&

Professional Papers

1963

\title{
Influence of successive habit reversals on human learning and transfer
}

Nancy Trask Paul

The University of Montana

Follow this and additional works at: https://scholarworks.umt.edu/etd Let us know how access to this document benefits you.

\section{Recommended Citation}

Paul, Nancy Trask, "Influence of successive habit reversals on human learning and transfer" (1963). Graduate Student Theses, Dissertations, \& Professional Papers. 5006.

https://scholarworks.umt.edu/etd/5006

This Thesis is brought to you for free and open access by the Graduate School at ScholarWorks at University of Montana. It has been accepted for inclusion in Graduate Student Theses, Dissertations, \& Professional Papers by an authorized administrator of ScholarWorks at University of Montana. For more information, please contact

scholarworks@mso.umt.edu. 


\section{INFLUENCE OF SUCCESSIVE HABIT REVERSALS}

ON HUMAN LEARNING AND TRANSFER

by

\section{NANCY TRASK PAUL}

B.A. Montana State University, 1958

Presented in partial fulfillment of the requirements

for the degree of

- Master of Arts

MONTANA STATE UNIVERSITY

1963

Approved by:

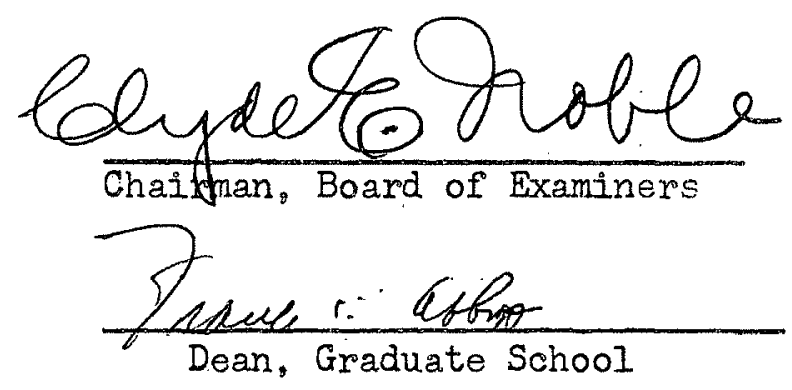

AUG 231963

Date 
UMI Number: EP40470

All rights reserved

INFORMATION TO ALL USERS

The quality of this reproduction is dependent upon the quality of the copy \$ubmittec

In the unlikely event that the author did not send a complete manuscript and there are missing pages, these will be noted. Also, if material had to bedremove a note will indicate the deletion.

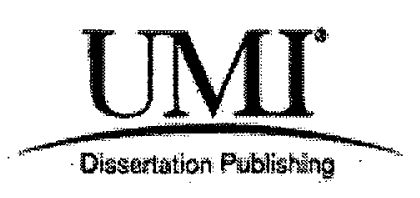

UMI EP40470

Published by ProQuest LLC (2014). Copyright in the Dissertation held bydhe Aut Microform Edition (C) ProQuest LLC.

All rights reserved. This work is protected against unauthorized copying under Title 17, United States Code

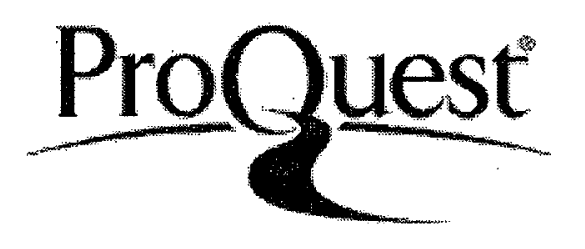

ProQuest LLC.

789 East Eisenhower Parkway

P.O. Box 1346

Ann Arbor, MI 48106 - 1346 


\section{ACKINOWLEDGMENT}

I. wish to thank Dr. Clyde E. Noble for

his invaluable assistance and guidance of this research. Grateful acknowledgment is made to all others who assisted with this study.

NTP. 
TABLE OF CONTENTS

Section Page

Introduction................................. 1

Method....................................... 4

Apparatus.................................... 4

Subjects..................................

Procedure................................... 5

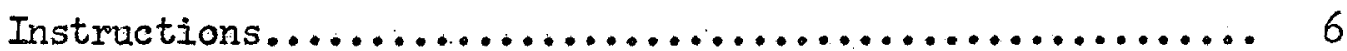

Results..................................... 8

Discussion..................................... 11

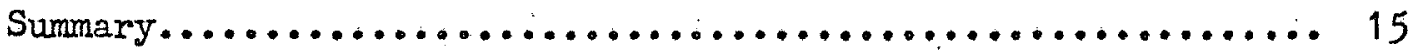

References.................................... 1?

Figures.................................... 20

Tables....................................... 22 


\section{INTRODUCTION}

Experimental and theoretical interest in the transfer and habit reversal aspects of selective learning originated in the domain of animal behavior (Hull, 1952; Kimblie, 1961). The principal tasks investigated have been of the simple trial-and-error type, employing two-choice, singlemut problems such as the T-maze. Recently, Noble (1957a) began an experimental program designed to orient human selective learning research around the more complex class of sequential tasks known as compound trial-and-error learning. The problem to be analyzed here was concerned with the transfer consequences of repeatedly reversing habit patterns on the Selective Mathometer; $i$. $e .$, with the phenomena of learning to learn (Harlow, 1959) in non-verbal, serial multiple-choice situations..

Both classical and instrumental conditioning studies have shown that acquisition rates increase as a function of increased general experience with a task. In dogs Pavlov (1927) found a direct relationship between the number of previous non-reinforcements of a conditioned salivary reflex and its rate of extinction. Finch and Culler (1935) reconditioned flexion reactions in about ond fourth of the original trials, and Hilgard and Marquis (1935) reported similar data for the canine eyelid response. Studies of successive conditioning and extinction were performed by Brogden, Lipman, and Culler (1938) on dogs, and by Bullock and Smith (1953) on rats in a Skinner Box, all with positive results. Habit reversal. in selective learning began with a controversial 1930 study by Buytendijk (Krechevsky, 1932), in which he achieved eventual one-trial 
reversals in rats. This was substantiated by Dufort, Guttman, and Kimble (1954). The problem was then extended to primate learning, whereupon experiments revealed that both: monkeys (Harlow, 1949) and chimpanzees (Nissen, Riesen, \& Nowlis, 1938) were able to master one-trial reversals. Reversing the reward values of stimulus cues has been quite common in single-unit simple selective learning, but investigations of changing reward sequences in multiple-unit compound selective learning have been limited, particularly in the human species. Noble, Alcock, and Farese (1958) performed two experiments to determine the effects of reversing well-learned habit patterns on the Selective Mathometer under two degrees of specificity of instructions. They predicted that performance on the first post-reversal trial would drop to chance and that a learning-tolearn facilitation would appear in both groups. Their results substantiat. ed this prediction, with the standard (more specific) instruction group being superior. Evidence concerning the influence of multiple-task experience upon transfer of training in human $\underline{S}$, however, has not been as consistent as the animal data (Crafts, 1927; Dashiell, 1924; Harlow, 1959). An example of this occurs in a study by Adams (1954), in which he trained two groups of airmen to solve simple four-choice discrimination problems by the non-correction procedure. One group was trained on different problems, the other on the same problem, for 24 blocks of trials. Both groups were then tested on a new problem for three blocks of trials. Adams! results clearly indicated that single-problem training facilitated learning the new task more than multiple-problem training did. In a similar experiment, but using a different apparatus and method, Duncan (1958) varied the amount of training and the number of tasks in college students. After a minimum delay of $24 \mathrm{hrs.,} \mathrm{each} \mathrm{group} \mathrm{was}$ 
tested on two new tasks. Duncan's results showed that the greater the number of different tasks the better the performance, and there was no interaction between amount of training and the number of different tasks. Possible reasons for the lack of agreement between the Adams and Duncan studies are many, and indicate a need for further research.

The present investigation was designed to contribute more extensive data to the literature on human learning and transfer employing successive habit reversals as the means of providing generalized learningto-learn experience. As in the Noble, Alcock, and Farese (1958) experiment, this one will attempt to describe all of the acquisition, reversal, and transfer functions by a single mathematical model. The rational equation proposed to describe these curves (Noble, 195\%) has the form:

$$
R_{p}=a(i)^{r^{N}}
$$

where $R_{.}=$probability of a correct first choice $(\underline{R}+) ; \underline{a}=$ asymptote of $\underline{p}$ $R_{p}$ taken as $1.00 ; \underline{i}=$ initial probability of $\underline{R}+$ given by the reciprocal of the number of available responses $\left(1 / \mathbb{N}_{R}\right) ; \underline{r}=$ rate parameter determined by the number of prior reversals, and $\underline{N}=$ number of reinforced trials.

The first prediction was for the Training Phase: Trials $1-80$. Upon reversal of the correct $S-R$ sequence, the Reversal Group should drop immediately to a chance level; i. $e_{0}, \underline{R}_{\mathrm{p}}=\underline{\underline{i}}=1 / \mathrm{N}_{\mathrm{R}}$. Following this there should be a learning-to-learn facilitation, with each postireversal acquisition curve starting higher and rising faster than its immediate pre-reversal curve; thus, there will be systematic changes in the $\underline{i}$ and $\underline{\underline{r}}$ parameters in Equation 1 for every eurve of the Reversal Group. The second prediction was for the Transfer Phase: Trials 81-90.. It was hypothesized that the amount of transfer to a new problem would 
vary directly with the amount of reversal training, and that it would be positive in nature. Both groups should drop to a chance level just bea fore the first test trial of the Transfer Phase, but there ought to be a faster rise (lower $\mathbf{x}$ parameter) for the Reversal Group than for the Stan dard Group. A final prediction was that, because of this differential transfer of learning-to-learn effects, the Reversal Group should make fewer overt errors (-) than the Standard Group during the Transfer Phase. METHOD

Apparatus. The learning device was the Selective Mathometer, an automatic 19-key multiple-choice apparatus designed for the study of complex human learning. It is fully described elsewhere (Noble, Fuchs, \& Thompson, 1963; Noble \& Farese, 1955). The $\underline{S}$ was confronted with four visual stimuli (circuit symbols) presented serially by an electronicallycontrolled slide projector. He responded by selecting a particular key from the ten available, odd-numbered keys which were mounted on a semim circular panel directly in front of him. A correct choice ( reinforced by a green light mounted directly above the keys and below the screen. Overt errors $(\underline{R}-)$, omissions, or late choices were not reinforced. Each stimulus was presented for a period of 2 sec. with a 2 sec. interstimulus interval. The reward light came on immediately and lasted for .75 sec. Data were collected by magnetic counters and by continuous graphic recordings. In addition to the onset, duration, and rate of stimulus presentation, the time of oceurrence, sequence and duration of all responses was recorded.

Subjects. The sample was composed of 88 Montana State University students selected from undergraduate psychology courses. There were 59 men and 29 women, whose ages ranged from 17 to 46 (mean $=23.8 \mathrm{yrs}$. ). 
All Ss were maive with respect to the Mathometer. They were assigned equally and without bias to two groups: the Reversal Group $(R)$ and the Standard Group (S).

Procedure. The Ss were run in a simple counterbalanced order on arrival at the laboratory $(\underline{n}=44$ each). Groups $R$ and $S$ were presented the four stimuli in an invariant sequence with ten available responses (Keys 1, 3, 5, 7, 9, 11, 13, 15, 17, 19) present, of which Keys 1,7. 13, 19 were relevant (reinforceable) during the Training Phase. The stimulus sequence was the same for all $\underline{S}$ in all groups on all trials (1-90). A trial was defined as four stimulus presentations, and a trial block contained 10 such trials. Twenty-two permutations of the 4 -link, 10-choice problem were used for both groups, excluding the left-right and right-left sequences. Two Ss were assigned to each permutation.

Condition $S$ presented a standard task containing an invariant response permutation for 80 trials. In Condition $R$ the response sequence was reversed at the termination of each block of trials for the next 10 trials. For example, the response sequence for Trials $1-10$ of Keys $7 \rightarrow 13 \rightarrow 1 \rightarrow 19$ became $19 \rightarrow 1 \rightarrow 13 \rightarrow 7$ on Trial 11 and continued through Trial 20. On Trial 21 the sequence was the same as during the first block, and so on in simple alternation throughout the Training Phase. At the termination of Trial 80 both groups of $\underline{S}$ were presented with a unique task for the Transfer Phase. This new problem was introm duced for 10 additional trials to provide a measure of the transfer effects of the two different training methods. Keys 3, 5, 15, 17 , never correct before, now became the relevant keys for Trials 81-90. The nature of the response sequence for both conditions was "tumed inside out" for Trials 81-90. For example, a sequence on Trial 80 of Keys $7 \rightarrow 13 \rightarrow 19 \rightarrow 1$ 
became Keys $15 \rightarrow 5 \rightarrow 3 \rightarrow 17$ on Trial 81 . This change was accomplished by merely switching the ordinal positions of the new keys so that the second became first, and the fourth became the third in the series.

Instruations. The following standard instructions were read to both groups of $\underline{S} s$ :

"This is a test of your ability to learn. Four symbols will appear one at a time on this screen. (E points to the screen.) Here are a number of buttons. (E points to the buttons.) As each symbol comes on the screen, your job will be to find out which button is connected with the symbol on the screen. In order to do this, you must press down on a button like this. (E presses a button, all buttons being pressed an equal number of times.) If the button you press down on is connected with the symbol on the screen, this green light will flash on. (E points to the reward light.) If the green light does not flash on when you press down on the button, it means that particular button is not cons nected with the symbol on the sereen.

"Now remain here at the keyboard, and I will go into the next room and talk to you through the intercom. This is a one-way vision mirror. (E points to the mirror.) It allows me to observe your progress without distracting you. (E leaves $\underline{S}^{\prime} s$ charber and goes to the adjacent chamber containing the apparatus.) Gan you hear me clearlys (If not, E adjusts the volume until reception is elear.) It is important that you make a choice every time a symbol appears, but only one choice. You must make this one choice while the symbol is on the screen. Do not press any buttons when there is nothing on the screen. Try to find the correct button for each symbol as quickly as possible. The same series of four symbols will be shown over and over a number of times. Between 
each series there:will be a short rest interval. The object is to press the correct button as quickly as possible, but, and this is important, you should triy to do so with as few mistakes as possible. The entire test will take about $50 \mathrm{~min}$. Are there any questions so far? When the experiment begins I cannot answer any questions, but I will be glad to answer any you may have when we have completed the experiment.

"Now I want to show you how to press the buttons. When pressing a button, use the forefinger of either hand, but use the same hand throughout the test. Which hand will you use? Now stick out your hand as if you were pointing. Press a button. When pressing a button, press it lightly, and do not hold the button down. Between slides keep your forefinger on the metal disk at the bottom of the keyboard panel. You goal is to turn on as many green lights as possible during the test. We are now ready to begin the test. The same slides will be shown at the same rate. Remember, your job will be to find out which button is connected with each symbol on the screen. You must work fast to keep up. Ready? Here is the first symbol. Make your first choice."

At the end of the experiment Ss were told: "That is the end of the experiment. Please do not discuss the procedure with anyone. Thank you." The supplementary comment, "Let's try another problem now.", was made to Group $R$ during each inter-trial interval following Trials 10. $20,30,40,50,60$, and 70 . Following Trial 80 , the following instructions were given to both groups: "Let's try another problem now. The buttons which were used before will not be correct now." No hint was given by $\underline{E}$ as to the nature of the new task. The non-correction procedure was used throughout the experiment. 
RESULTS

The general results of this investigation are presented in Fig. 1 in the form of pooled acquisition curves for the two experimental groups.

\section{Insert Fig. 1 here}

The empirical probability of making a correct choice $\left(R_{p}\right)$ is plotted as a function of the number of trials (N), along with theoretical curves calculated from Equation 1. Experimental $R_{p}$ scores were computed as a ratio of the total number of correct responses ( $\underline{R}+$ ) achieved per trial relative to the maximum possible $\underline{R}+$ score for either group: $R_{p}=\Sigma R+/ 176$. To evaluate the possibility of initial differences between the two groups a $10 \times 2$ mixed-factorial Type I analysis of variance test (lindquist, 1953) was applied to the Rt data of Group $S$ and Group R during Trials 1-10. The sumary shown in Table 1 indicates that the only significant source

\section{Insert Table 1 here}

of variance is the main effect of Trials $(\underline{P}<.001)$. Neither the Conditions effect nor the Trials $x$ Conditions interaction produced an $F$ ratio greater than unity, so one may regard the two samples of $\underline{S}$ s as. statistically equal in ability before introduction of the experimental treat. ments. For this reason the theoretical curve of Group $R$ is not shown in Fig. 1 .

As expected, both groups originated close to chance $(\underline{i}=.10)$ on the first block of trials in the Training Phase and approached mastery accordIng to the mathematical characteristics predicted from Equation 1. It will be noted that the origin of the first reversal of Group $R$ (Trial 11) is somewhat lower than the 1 value of Trial 1, but this is not a significant 
drop $(\underline{t}=1.42$, $\underline{\mathrm{d} f}=43)$. In agreement with hypothesis, the $\underline{\underline{i}}$ values of all subsequent reversal curves and the $\underline{x}$ parameters of all curves but one spowed a steady change from the second block to the eighth block of the Training Phase; 1 . e., from Trial 11 to Trial 80. These data are presented

Insert Table 2 here

in the third and fourth columns of Table 2 .

Presented below are the eleven equations used in constructing the smooth theoretical curves of Fig. 1, arranged in the same order as found in Table 2:

Group S, Trials 1-80: $R_{p}=1.00(.100)^{.836}$

Group R, Trials 1-10: $R_{p}=1.00(.100) .844^{N}$

Group R, Trials 11-20: $R_{p}=1.00(.074) \cdot 749^{N}$

Group R, Trials 21-30: $R_{p}=1.00(.210) \cdot 757^{N}$

Group $R$, Trials $31-40: R_{p}=1.00(.335) \cdot 701^{N}$

Group R, Trials 41-50: $R_{p}=1.00(.381) \cdot 653^{N}$

Group R, Trials 51-60: $R_{p}=1.00(.494)^{.621^{N}}$

Group R, Trials 61-70: $R_{p}=1.00(.585) \cdot 583^{\mathrm{N}}$

Group R, Trials 71-80:

$R_{p}=1.00(.642) \cdot 576^{N}$

Group R, Trials 81-90:

$R_{p}=1.00(.100) \cdot 636^{N}$
$R_{p}=1.00(.100) \cdot 734^{N}$

Group S, Trials 81-90: $R_{p}=1.00(.100) \cdot 734^{N}$

As a measure of goodness of fit, an index of determination ( $\underline{\alpha}=100 \sigma^{2} / \sigma^{2}$ ) was computed for each of the theoretical curves by the method given in Noble (1957b). The statistic $\underline{d}$ is analogous to the coefoident of determination in linear regression, and specifies the percentage of variance in the dependent variable $\left(R_{p}\right)$ which is predicted by Equation 1. These values range from $99.49 \%$ for Trials 1.80 of Group $S$ to $64.60 \%$ for Trials 
$71-80$ of Group $R$, with a median predictability of $97.22 \%$ for all 11 curves obtained in the experiment.

At the beginning of the Transfer Phase the $R_{p}$ values on Trial 81 fell in the expected manner, both groups dropping immediately to a nearchance level. The $R_{p}$ value for Group $R(.210)$ was somewhat higher than the value for Group $S(.148)$, but not significantly so $(\underline{t}=1.41$, df $=86)$. To determine whether a learning-to-learn effect was measureable on the first trial of the Transfer Phase, a $t$ test between Trial 1 and Trial 81 was performed on the data of each group separately. This difference was significant for Group $R(\underline{t}=2.32, \underline{d f}=43, \underline{P}<.05)$, but not for Group $S$ $(\underline{t}=.52$, $\underline{d f}=43)$. When the entire Transfer Phase is considered, however, Table 2 reveals smaller $\underline{\underline{r}}$ parameters for Trials 81-90 than for Trials 1-10 in both cases. Because the magnitude of the rate: parameter in Equation 1 is inversely related to the visual slope of the curve, this more extended trend analysis is quite consistent with our general knowledge of learning-to-learn phenomena. It is also in conformity with previous Mathometer findings (Noble, Alcock, \& Farese, 1958).

To evaluate the test of transfer, a $10 \times 2$ analysis of variance was conducted on the number of correct responses ( $\underline{R}+$ ) made by the two groups from Trial 81 to Trial 90. As show in Table 3, the main effects of Trials,

Insert Table 3 here

Conditions, and the Trials $\mathrm{x}$ Conditions interaction are all significant... $(\underline{P}<.01)$. The latter two $\underline{E}$ ratios support the hypothesis that the Reversal Group would be superior to the Standard Group during the Transfer Phase. Table 2 and Fig. 1 also provide evidence of differential trends in the rate parameters for Groups $R$ and $S$. Finally, there was a confirmation of 
the prediction of fewer overt errors (․-) by the Reversal Group in this. same period. Mean $\underline{R}$ - scores from Trials 81-90 were 16.04 for Group $S$ and 11.25 for Group R. This difference is significant ( $\underline{t}=2.90$, $\underline{\mathrm{df}}=86, \underline{P}<.01)$.

To determine the nature of the extinction of formerly correct responses, $R_{p}$ scores of responses which were correct during the previous acquisition phase were computed for each reversal block beginning with Trial 11. These data are presented in Table 4. Also, $R_{p}$ values of

Insert Table 4 Here

previously correct responses during the Transfer Phase are shown for both groups. The extinction data for Group $R$ were scored so as to include responses which were in the correct sequence for both the initial problem and its reversal. This scoring technique reflected the fact that the Reversal Group received the same number of training trials on the "forward" and "backward" sequence of responses now undergoing extinction in the Transfer Phase. To determine the relationship between extinction and acquisition a Spearman rank order correlation (rho) between formerly correct responses and correct responses ( $\underline{R}+$ ) was obtained and found to be a perfect negative correlation (rho $=-1.00$ ).

\section{DISCUSSION}

The results of the Training Phase provide quantitative support for the conclusion that 4-unit, 10-choice trial-and-error learning problems requiring successive reversals of the correct response sequence are acquired by human $\underline{S}$ s according to the same mathematical equation as standard trial-and-error learning. All curves of the Reversal Group and the Standard Group during this period wepre consistent with the rational 
equation $R_{p}=a(1)^{r^{N}}$, and the indices of determination ranged from $64.60 \%$ to $99.49 \%$. As predicted, there was a learning-to-learn facilitation produced by the Reversal conditions which, in general, caused each succeeding block of curves to begin with a higher $R_{p}$ value and to rise at a faster rate than its predecessors. The two acquisition curves of the Transfer Phase were also consistent with the mathematical model. They agreed with the expectation that, upon presentation of a new 10-choice problem requiring the use of four hitherto irrelevant keys, both groups should fall to chance $(\underline{i}=.10)$ then transfer positively, with the Reversal Group superior in rate of acquisition to the Standard Group.

Data showing cumulative improvement in selective-learning performance as a function of successive intra-problem reversals have been reported on a variety of samples from rats (North, 1950a; North, 1950b; Dufort, Guttman, \& Kimble, 1954), to monkeys (Harlow, 1959; Meyer, 1951), to human aments (House \& Zeaman, 1959), to college students (Noble, Alcock, \& Farese, 1958). These facts are generally acknowledged to fall within the domain of learning-to-learn phenomena; $i . e .$, they are classified as involving the formation of learning sets (Harlow, 1949). With respect to the question of differential positive transfer to new problems, however, the human experimental Itterature has been inconelusive (Adams, 1954; Duncan, 1958), due mainly to apparatus and methodological differences. The present findings appear to confirm the pervasitreness of the learning-to-learn principle by demonstrating significant evidence of greater cross-task or inter-problen transfer for $S s$ who have had eight blocks of alternating 10-trial reversals than for $\underline{S} s$ who have had the same number of trials under standard conditions.

Two interesting aspects of the data are worthy of comment, First, 
the inter-trial variability of the Reversal Group tends to increase during the Training Phase and to be greater than that of the Standard Group during the Transfer Phase. Evidence of this is seen in the goodness-of-fit indices recorded in Table 2 and in the empirical points plotted in Fig. 1. This effect may be related to the principle of oscillation (Hull, 1952), whereby changing stimulus conditions would be expected to produce greater response variability among Ss practicing under the Reversal conditions. Independent support for this conjecture has been reported in a previous Mathometer experiment (Farese \& Noble, 1960).

The second notable observation in the present study is best appreciated by reference to Fig. 1, where there is excellent visual evidence for the S-R reinforcement theorist's hypothesis that the learning process is fundamentally continuous rather than discontinuous, as held by $S_{\infty} S$ contiguity theorists of the Gestalt school (Kimble, 1961). If the hallmark of insight is taken to be suddenness of solution, qaintenance of the correct responses, and easy transfer to another problem (Woodworth \& Schlosberg, 1954, p. 824), then insight will have to be considered as the outcome of leaming to learn. Not only do initial probabilities and rates of gain increase progressively for the Reversal Group as a result of varied experience with the same problem, but this type of experience also transfers in greater magnitude to a new problem, as compared with the performance of the Standard Group. The successive transfer functions manifest all the earmarks of insightful behavior as commonly understood by cognitively-oriented psychologists. Initial periods of positive acceleration are no longer visible after the third reversal. (Trials 31 40) of Group $R$, and the curves of the last two reversals are quite steep. 
Although no group curves attained the one-trial criterion, several individual Ss did so. This ability was reached, however, only after extended reversal training. The number of $\underline{S} s$ in Group $R$ who obtained perfect scores on the second pest-reversal trial of each block during the Training Phase are shown in parentheses as follows: Trial 12 (.1), Trial 22 ( 5), Trial 32 ( 8 ), Trial 42 ( 16$)$, Trial 52 ( 26$)$, Trial 62 (27). Trial 72 (29). Consistent with continuity theory, the likelihood of individual Ss achieving one-trial reversals is a cumulative function of practice.

The extinction data presented in Table 4 are similar to those obtained in animal studies of successive conditioning and extinction. The formerly correct responses generally commence at a lower $R_{p}$ value for each succeding reversal block than for the previous reversal block. The rate of extinction also progressively increases with each block until these erroneous responses are no longer made. Unlike the animal studies which utilized a two-choice situation, the extinction data reported here were obtained from a multiple-choice task. Although $\underline{S}$ sere not restricted to making errors by selecting formerly correct keys on the Mathometer, . they actually tended to prefer those particular response patterns among all of the others available. Harlow's (1959) uniprocess theory assumes that learning-to-learn phenomena involve nothing more than the inhibition of all error-producing factors and the ppsitive transfer of such inhibition. That is, there is no learning by reinforcement during reversal training. According to this notion, one should not expect to find the consistent repetition of responses which were formerly correct, but rather a random selection of all erroneous keys until extinction is complete. Instead of a zero correlation between the successive number of "forward" and "backward" sequences, there is a perfect negative correlation between 
these responses patterns. It would appear, therefore, that the present evidence of counter-conditioning cycles poses an embarrassment to Harlow's simple extinction explanation. Apparently, data collected from multipleunit, compound selective learning tasks may necessitate a revision of the uniprocess theory.

\section{SUMMARY}

This investigation analyzed the effects on training and transfer of reversing a habit pattern in complex human trial-and-error learning. Two equivalent groups of 44 Ss each practiced a series of 4-link, 10-choice tasks on the Selective Mathometer. The same problem was presented to the Standard Group for 80 trials. The problem for the Reversal Group was reversed after every 10 trials for eight blocks of such trials. Initial levels of responding and rates of gain for each reversal block after the first rose progressively throughout the Training Phase. Both groups received a new problem as a transfer task on Trial 81 and practiced it for 10 trials. As expected, the Reversal Group performed significantly better than the Standard Group during the Transfer Phase.

Response probability curves $\left(R_{p}\right)$ were plotted as a function of reinforced trials (N) for both conditions. A median goodness-of-fit value of $97.22 \%$ resulted from applying the rational equation $R_{p}=a(i){ }^{N^{N}}$ to the 11 durves in the experiment. Inter-trial variability of the Reversal Group caused the equation's index of determination to be generally lower than for the Standard Group. This effect was related to Hull's principle of oscillation.

Evidence favored S-R reinforcement theorists' interpretation of learning as a continuous rather than a discontinuous, process, as held by S-S contiguity theorists. Both individual and group data suggested that 
insightful behavior in reversal situations develops gradually as an outcome of the learning-to-learn process and is not fundamentaily different from ordinary trial and error learning. 


\section{REFERENCES}

Adams, J. A. Multiple vs. single problem training in human problem solving. J. exp. Pstahol.. 1954, 48, 15-18.

Brogden, W. J., Lipman, E. A., Culler, E. The role of incentive in conditloning and extinction. Amer. J. Psychol.. 1938, 51. 109-117. Bullock, D. H., \& Smith, W. C. An effect of repeated conditioningextinctilon upon operant strength. I. exp. Psychol., 1953, 46. $3495 \%$

Crafts, L, W. Routine and varying practice as preparation for adjust. ment to new situations. Arch. Psychol., N. I., 1927, 14, No. 91.

Dashiell, J. F. An experimental isolation of higher level habits. J. exp. Psychol., 1924, 7, 391-397.

Dufort, R, H., Guttman, N., \& Kimble, G. A. One-trial discrimination reversal in the white rat. J. comp. physiol. Psychol. 1954, 47, $248-249$

Duncan, C. P. Transfer after training with single vs. multiple tasks. J. exp. Psychol., 1958, 55, 63-72.

Farese, F. J., \& Noble, C. E. Trial-and-error vs. mixed-selective learning in man. Percept. mot. Ski11s, 1960, 10, 115-122.

Finch, G., \& Culler, E. Relation of forgetting to experimental extinction. Amer. J. Psychol., 1935, 47, 656-662.

Harlow, H. F. The formation of learning sets. Psychol. Rev., 1949 , $56.51-65$.

Harlow, H. F. Learning set and error factor theory. In S. Kooh (Ed.), Psychology: A Study of a Science. New York: MoGraw-Hill, 1959. Pp. 492. 537. 
Hilgard, E. R., \& Marquis, D. G. Acquisition, extinction, and retention of conditioned lid responses to light in dogs. J. comp. Psychol., 1935, 19, 29-58.

House, B. J., \& Zeaman, D. Position discrimination and reversals in low-grade retardates. J. comp. physiol. Psychol., 1959, 52, $564-565$.

Hull, C. L. A behavior system. New Haven:Yale Univer. Press, 1952. Kimble, G. A. Hilgard and Marquis' Conditioning and Learning. (Rev. Ed.). New York:Appleton-Century-Crofts, 1961.

Krechevsky, I. Antagonistic visual discrimination habits in the white rat. J. comp. Psychol. $1932,14,263-277$.

Lindquist, E. F. Design and analysis of experiments in psychology and education. Boston:Houghton Mifflin, 1953.

Meyer, D. R. Food deprivation and discrimination reversal learning by monkeys. J. exp. Psychol., 1951, 41, 10-16.

Nissen, H. W., Riesen, A. H., \& Nowlis, V. Delayed response and discrimination learning by chimpanzees. J. comp. Psychol., 1938, 26, $361-386$.

Noble, C. E. Human trial-and-error learning. Psychol. Rep., 1957. 3. 377-398. (Monogr. Suppl. 8) (a)

Noble. C. E. The length-difficulty relationship in compound trialand-error learning. J. exp. Psychol. 1957, 54, 246-252. (b) Noble, C. E., Aleock, W. T., \& Farese, F. J. Habit reversal under differential instructions in compound trial-and-error learning. J. Psychol., 1958, 46, 253-264.

Noble, C. E., \& Farese, F. J. An apparatus for research in human selec. tive learning. J. Psychol., 1955, 39, 475-484. 
Noble, C. E., Fuchs, J. E., \& Thompson, J. D. A new automatic circuit for the selective mathometer (MKII). J. Psychol., 1963, $55,241-257$.

North, A. J. Improvement in successive discrimination reversals. J. comp. physiol. Psychol., 1950,43,442-460. (a)

North, A. J. Performence during an extended series of discrimination reversals. I. comp. physiol. Psychol., 1950, 43, 461-470. (b) Pavlov, I. P. Conditioned reflexes. London:0xford Univer. Press, 1927. Woodworth, R. S., \& Schlosberg, H. Experimental psychology. (Rev. Ed.) New York: Holt, 1954. 
Fig. 1. Response probability $\left(R_{p}\right)$ curves of the Standard and Reversal conditions as a function of reinforced trials (N). Each group contains 44 Ss. The fitted functions are rational. 


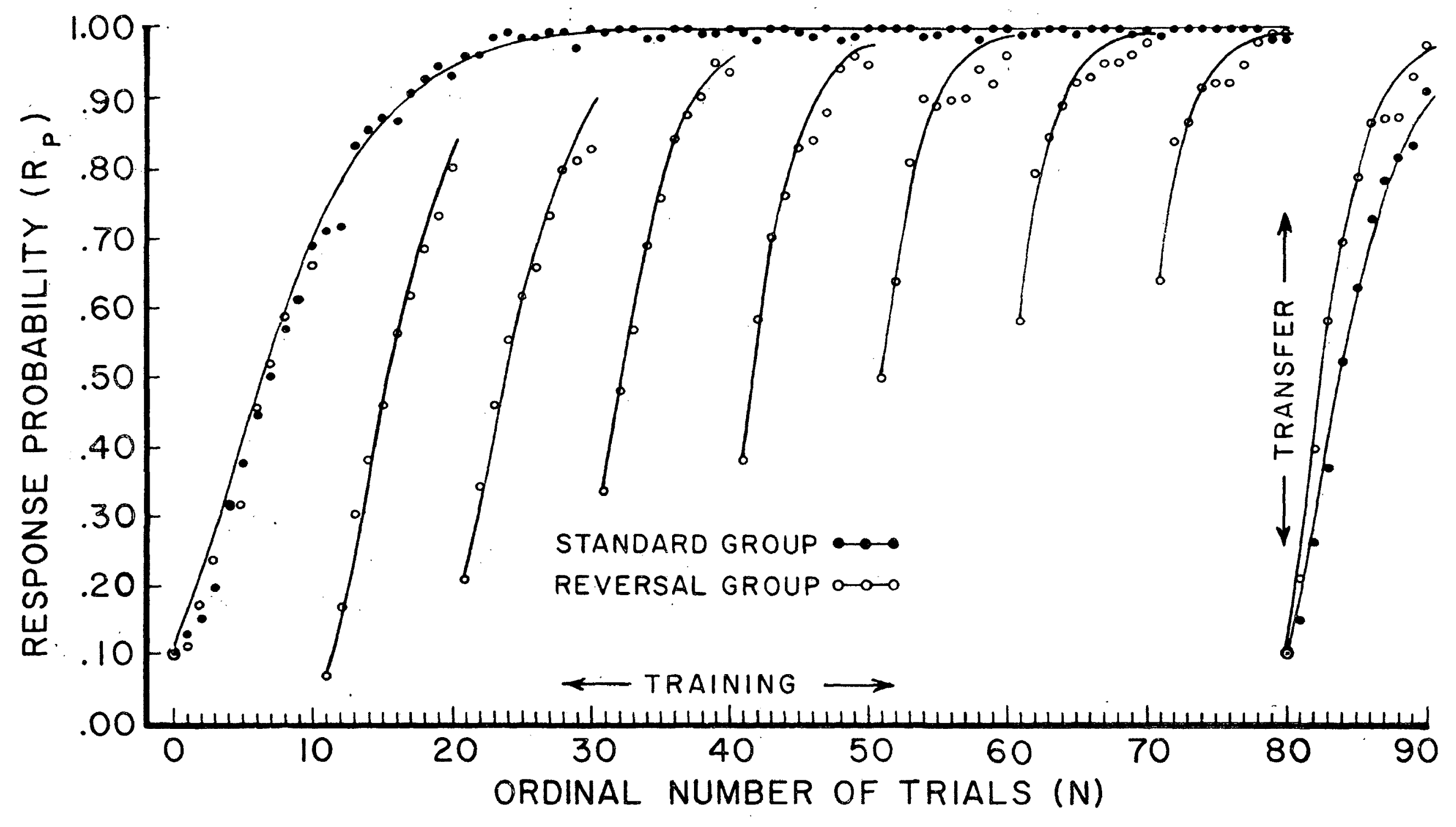




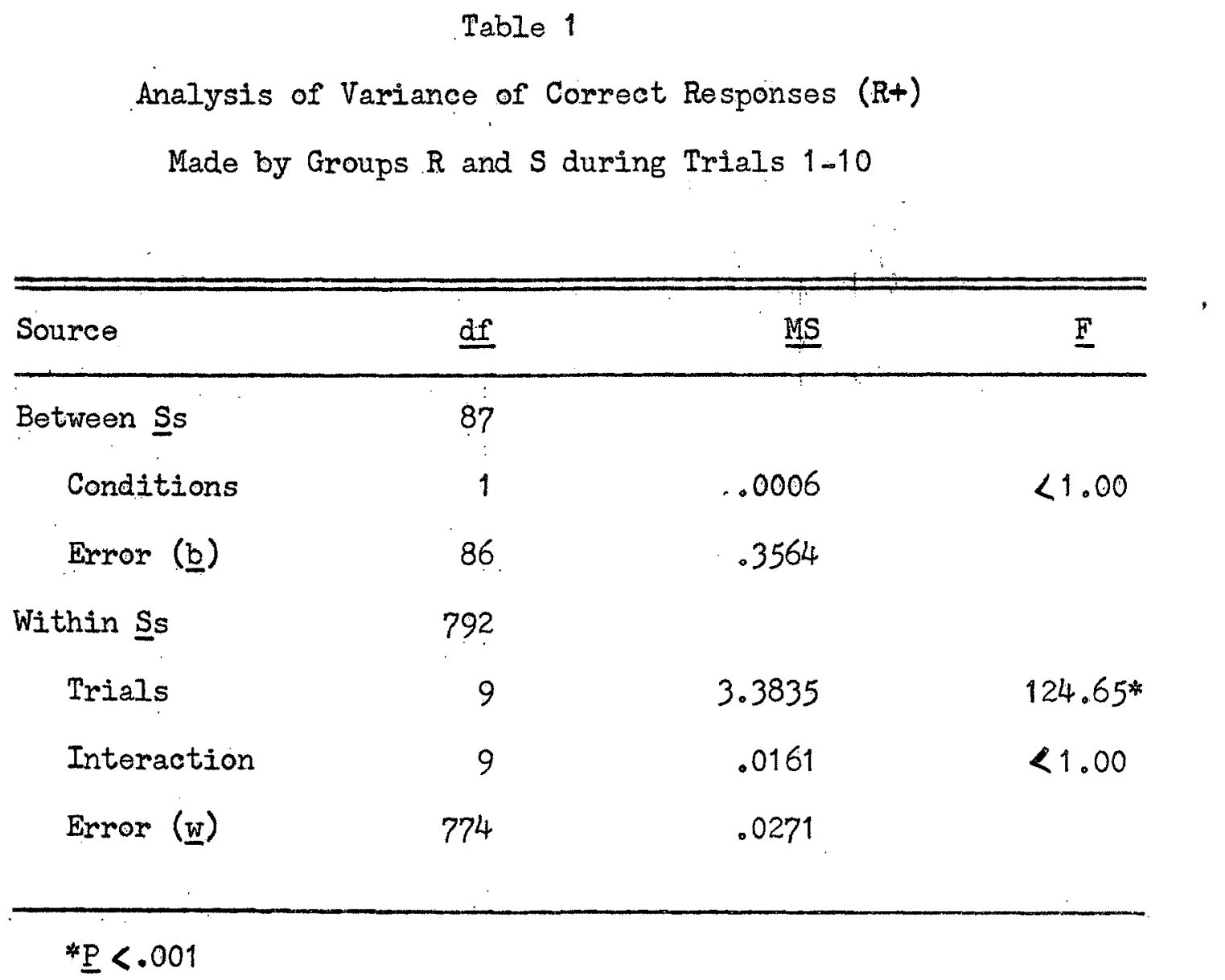


Table 2

Initial Probabilities (i), Rate Parameters ( $\underline{\underline{i}}$ ), and Goodness-of-Fit Indices (d) of the Curves for the Two Groups During Training and Transfer

\begin{tabular}{ccccc}
\hline Group & Trials & $\underline{1}$ & $\underline{\mathbf{r}}$ & $\underline{\mathrm{d}}$ \\
\hline $\mathrm{S}$ & $1-80$ & .100 & .836 & 99.49 \\
\hline & $1-10$ & .100 & .844 & 98.07 \\
& $11-20$ & .074 & .749 & 97.22 \\
& $21-30$ & .210 & .757 & 95.40 \\
$\mathrm{R}$ & $31-40$ & .335 &. .701 & 99.31 \\
& $41-50$ & .381 & .653 & 92.87 \\
& $51-60$ & .494 & .621 & 80.87 \\
& $61-70$ & .585 & .583 & 76.14 \\
& $71-80$ & .642 & .576 & 64.60 \\
\hline $\mathrm{S}$ & $81-90$ & .100 & .636 & 98.88 \\
\hline
\end{tabular}


Table 3

Analysis of Variance of Correct Responses (R+)

Made by Groups $R$ and $S$ during Trials 81-90

\begin{tabular}{|c|c|c|c|}
\hline Source & df & MS & $\underline{F}$ \\
\hline Between Ss & 87 & & \\
\hline Conditions & 1 & 3.2222 & $8.56 * *$ \\
\hline Error (b & 86 & .3765 & \\
\hline Within Ss & .792 & & \\
\hline Trials & 9 & 5.9065 & $165.74 * *$ \\
\hline Interaction & 9 & .0904 & $2.54 *$ \\
\hline Error (w) & 774 & .0356 & \\
\hline
\end{tabular}


Table 4

Analysis of Extinction Data for the Reversal Group

in Terms of $R_{p}$ Scores of Formerly Correct

Sequences During Acquisition Phase

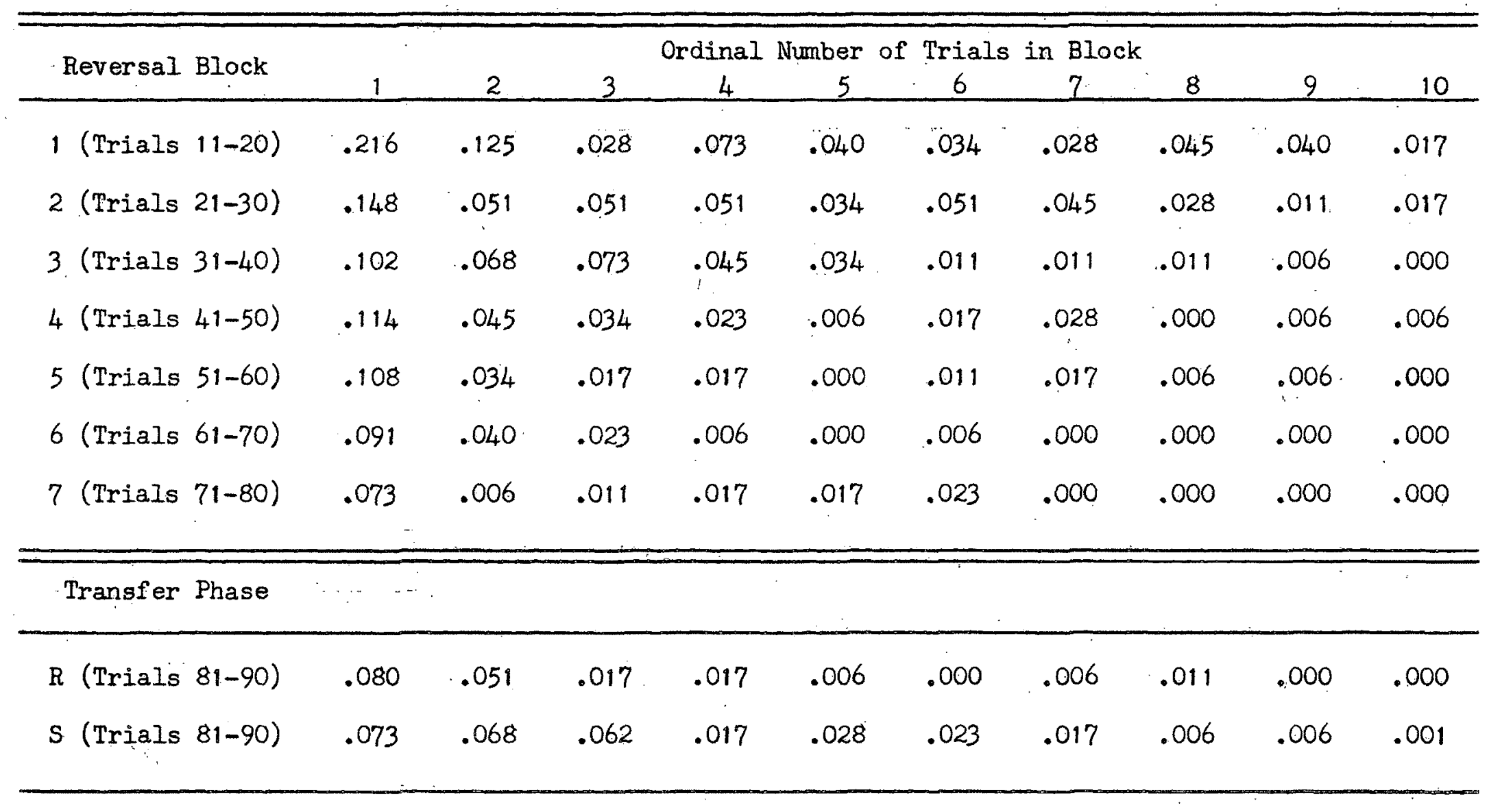

